Short Communication

\title{
Ultrafine Tin Dioxide Nanoparticles Grown on Nitrogen-doped Graphene with Rich Pyrrolic Nitrogen for Excellent Supercapacitor Performance
}

\author{
Gaosheng Nie ${ }^{1, *}$, Shizhen Dai ${ }^{2}$,Hangchun Deng ${ }^{2}$, Chunyan Wang ${ }^{2}$ \\ ${ }^{1}$ School of Internet of Things, Jiangxi Teachers College, YingTan, Jiangxi, 335000, China \\ ${ }^{2}$ East China University of Technology, Nanchang, Jiangxi, 330013, China \\ *E-mail: $\underline{\text { n18970187308@163.com }}$
}

doi: $10.20964 / 2020.09 .33$

Received: 7 May 2020 / Accepted: 8 July 2020 / Published: 10 August 2020

Composites of ultrafine tin dioxide nanoparticles grown on nitrogen-doped graphene $\left(\mathrm{SnO}_{2} @ \mathrm{NG}\right)$ with high pyrrolic nitrogen content are successfully prepared via a one-step method by employing graphene oxide, tin chloride, and urea as raw materials. Morphology and microstructure of $\mathrm{SnO}_{2} @ \mathrm{NG}_{\text {are }}$ characterized by transmission electron microscopy (TEM), X-ray photoelectron spectroscopy (XPS), and thermogravimetric analysis (TGA), revealing evenly dispersed $\mathrm{SnO}_{2}$ nanoparticles on the surface of nitrogen-doped graphene sheets and a $\mathrm{SnO}_{2}$ content of 54.23\%. The $\mathrm{SnO}_{2} @ \mathrm{NG}$ electrode exhibits a specific capacitance of $289.5 \mathrm{~F} / \mathrm{g}$ at a current density of $0.5 \mathrm{~A} / \mathrm{g}$ in $0.5 \mathrm{~mol} / \mathrm{L} \mathrm{Na}_{2} \mathrm{SO}_{4}$ solution and retains $92.85 \%$ of its initial capacitance after 2000 charge/discharge cycles. These results prove that $\mathrm{SnO}_{2} @ \mathrm{NG}$ is an excellent material for high-performance supercapacitors.

Keywords: tin dioxide, nitrogen-doped graphene, supercapacitors.

\section{$\underline{\text { FULL TEXT }}$}

(C) 2020 The Authors. Published by ESG (www.electrochemsci.org). This article is an open access article distributed under the terms and conditions of the Creative Commons Attribution license (http://creativecommons.org/licenses/by/4.0/). 